Egyptian

Orthodontic Journal

\title{
IDENTIFICATION OF POSTERIOR NASAL SPINE FOR ASSESSMENT OF HORIZONTAL MAXILLARY ROTATION
}

\author{
Amr labib*, Ashraf Fathy Mohammed ${ }^{* *}$, \\ Khaled Alloba ${ }^{* *}$
}

ABSTRACT:

Purpose: The aim of this study is the identification of posterior nasal spine (PNS) for assessment of horizontal maxillary rotation.

Materials and Methods: Five dry skulls were submitted for submentovertix cephalometric radiographs. Dental impressions were taken for the maxillae of these dry skulls and maxillary models were poured in extra hard stone. Data derived from cephalometric analysis were used for drawing reference line $\mathcal{L}$ points on the maxillary models. Finally, these maxillary models were compared with their corresponding actual maxillae $f$ the dry skulls to determine the accuracy of the PNS identification and the possibility of midline deviation.

Results: Two cases showed shift of maxilla to the left. One case showed midline deviation to the right. The remaining two cases showed identical palatal plane and skeletal midline which means that he maxilla is in the right relation to the rest of the skull.

Conclusion: Identification of the PNS and adjusting midline deviation of maxilla will perfect and enrich model surgery procedures.

\footnotetext{
* Amr Labib, Professor of Orthodontics, Cairo University.

*** Ashraf Fathy Mohammed, Associate. Professor of Oral and maxillofacial surgery, Minia university.

*** Khaled mohamed Allouba, Associate Professor of Radiology, Cairo university
} 
Egyptian

Orthodontic Journal

\section{INTRODUCTION}

Surgery of the facial skeleton involves complex three dimensional movements based on a series of non-surgical and surgical procedures. Bimaxillary osteotomies, which change the occlusal level to improve function and enhance physical appearance, require to be planned preoperatively with the help of model surgery. The use of an anatomical articulator with a facebow transfer for bimaxillary osteotomies is essential to achieve accuracy of the maxillary position in space and its relationship to the optimum functional centric occlusion ${ }^{1,2}$. The diagnostic information gained from preoperative clinical and radiographic assessment and model analysis is integrated to establish a treatment plan. This treatment plan is expressed in the model surgery, and the simulated post-operative model relationships are used to fabricate the intermediate and final occlusal wafers. These wafers are an essential means of transferring the treatment plan into an accurate surgical procedure ${ }^{3}$. However control of the positional change of the maxilla for bimaxillary surgery remains controversial as correct maxillary repositioning is essential for esthetic and functional outcome in orthognathic surgery ${ }^{4}$. If there is an abnormality in the inclination of the maxillary occlusal plane, it is difficult to achieve stability of functional occlusion. Ellis et $\mathrm{al}^{5}$ demonstrated a significant difference between the inclination of the occlusal plane on the mounted models and the actual occlusal plane as measured on the cephalograms.

The necessity of achieving a harmony of functional and esthetic aspects in such bimaxillary cases, will avoid abnormal inclination of the maxillary occlusal plane to be reformed and occlusion to be reconstructed ${ }^{6-8}$. One of the common errors in orthognathic model surgery occurs during face bow transfer and also may differ from one type of face bow to another. ${ }^{9,10}$.

Current methods of orthognathic surgical planning involve clinical evaluation, photographs, freehand surgical simulation based on cephalometric tracing and then transferred to study model surgery. Recently, computerized prediction software has accelerated the rate of progress in orthodontics \& orthognathic surgery beyond comparison with the pace of progress in the past ${ }^{11,12}$. 
Also a newly developed 3D computer-aided design (CAD) system is used for the diagnostic set-up of casts in orthodontic diagnosis and treatment planning. Although it is suggested that dental models with an accurate shape can be obtained with this system, at least in the clinical application, further studies using a rigorous system will be needed to improve the validity of measurement reliability ${ }^{13}$.

Midline deviation of the maxilla is always determined by measuring the distance between a line drawn between two central incisors (or ANS) and the skeletal midline drawn on PA cephalometric. Based on these data, the horizontal rotation of maxilla can be corrected. However, in cases of deviated palatal plane (ANS-PNS), where ANS coincide with the skeletal midline while PNS is not in midline, in such cases the posterior rotation of maxilla is missed and not corrected during preparation for model surgery. Therefore, precise simulation of the maxilla for model surgery is difficult depending on measurements taken from routine face-bow transfer, lateral and PA cephalometric radiographs ${ }^{14}$.

For this reason, a new and simple method for identifying PNS on the maxillary model has been projected before starting model surgery procedures. Identification of PNS will allow for precise correction of maxillary asymmetry.

\section{MATERIALS \& METHODS}

Subjects: Five dry skulls were used in our study. Each of these skulls will be submitted for submentovertix cephalometric radiographs which were done with a scale 1:1. Dental impressions were taken for the maxillae of these dry skulls and maxillary models were poured in extra hard stone.

\section{Submentovertix cephalometric analysis}

a. Celluloid acetate papers were used for tracing and measurements from the cephalometric radiographs.

b. A transspinosum axis (between the two foramen spinosum) is drwan then an interspinosum axis is drawn perpendicular to the transspinosum axis from its midpoint as the reference midline. A line connecting the 
ANS-PNS is drawn representing the palatal plane. A horizontal line is drawn from the tip of a palatal cusp of first or second molar to intersect with the palatal plane in a point $\mathrm{A}$. The same is done on the other side to have a point B on the palatal plane (Figure 1). Points A and B will be will be used to draw the palatal plane (ANS-PNS) on the maxillary model.

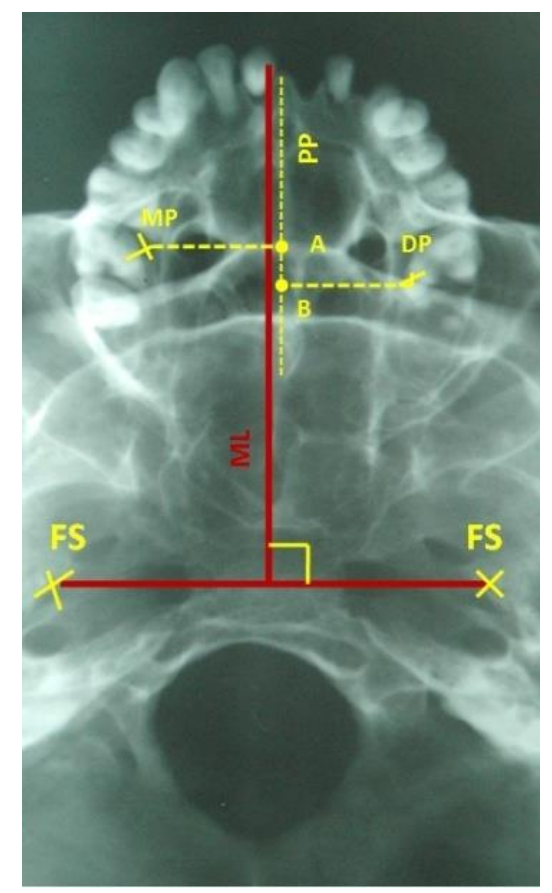

Figure 1. Submentovertix Ceph. A transpinosum line between the two foramen spinosum (FS) is drawn. Then, from its midpoint, a perpendicular line is drawn which represent the reference midline (ML). The dashed line connecting the ANS-PNS represents the palatal plane (PP). Point A represents intersect of a perpendicular from Mesiobalatal cusp tip of upper right second molar with palatal plane. Point B represents intersect of a perpendicular from distobalatal cusp tip of upper left second molar with palatal plane.

I. The measurements taken from the submentovertix cephalometric radiographs are drawn on the palatal surface of the maxillary model (Figure 2) as follow: 
1. A line is drawn horizontally from Mesiopalatal (MP)cusp tip of upper right molar toward palatalplane line (which is equal to MP-A) on submentovertix Cephalometric radiographs.

2. Another horizontal line is also done between Distoopalatal (MP)cusp tip of upper right molar toward palatalplane line (which is equal to DP-B) on submentovertix Cephalometric radiographs.

3. A line is drawn from point $A$ to point $B$ and extended posteriorly to intersect with the posterior border of the upper model in a point which represents the PNS. Extension of this line anetriorly will pass through the ANS.

4. The skeletal midline is also drawn on the palatal surface of the maxillary model using the palatal plane as a reference line.

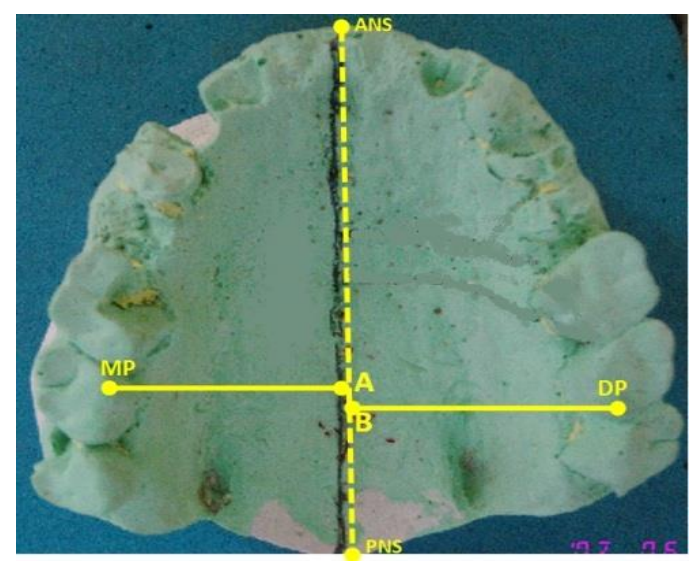

Figure 2. It shows the reference lines and points taken from submentovertix Cephalometric radiographs. ANS-PNS is the palatal plane. Point DP represents the tip of the distopalatal cusp of upper left second molar. Point MP represents the tip of the mesiopalatal cusp of upper right second molar. Points A and B represent intersects of two horizontal lines from MP and DP respectively with palatal plane.

III- All refernce lines and points were drawn on the palatal surface of the dry skull same as on the maxillary models with an exception that these reference lines and points were drwan on the actual landmarks on the skull, i.e; data from cephalometric analysis was not used (Figur 3). 


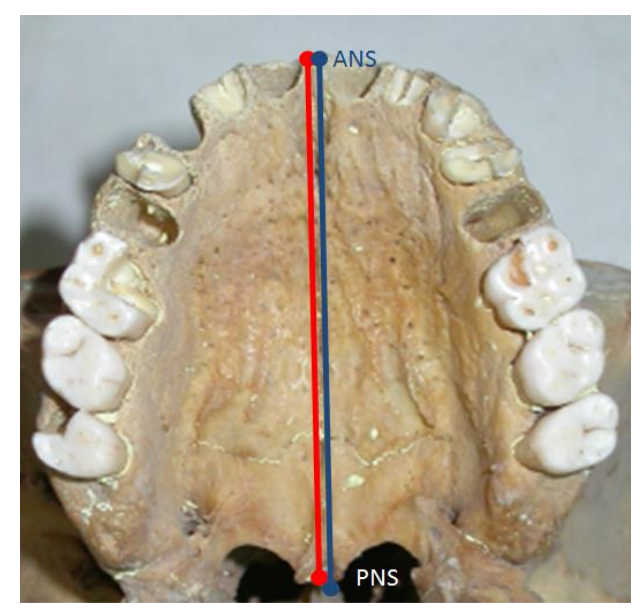

Figure 3. A line is drwan connecting between ANSand PNS represented palatal plane.Also another line is drwan representing skeletal midline using the same principles for midline identification in submentovertix cephalometric radiograph.

IV- Comparison between reference lines and points on the maxillary models and their corresponding dry skulls were done for PNS identification and assessment of any possibility of midline deviation

\section{RESULTS}

The comparisons done between reference lines and points on the maxillary model and the actual reference lines and points on the dry skull showed that all measurements were equal in all cases with an error less than $0.5 \mathrm{~mm}$. Two cases showed shift of maxilla to the left. In these two cases, both ANS and PNS on the model are positioned on the left side of the skeletal midline Figure 2. One case showed midline deviation to the right. In this case the ANS on the model and the dry skull are identical, but the PNS of the model is shifted to the right. The remaining two cases showed identical palatal plane and skeletal midline which means that he maxilla is in the right relation to the rest of the skull (Figure 4). 


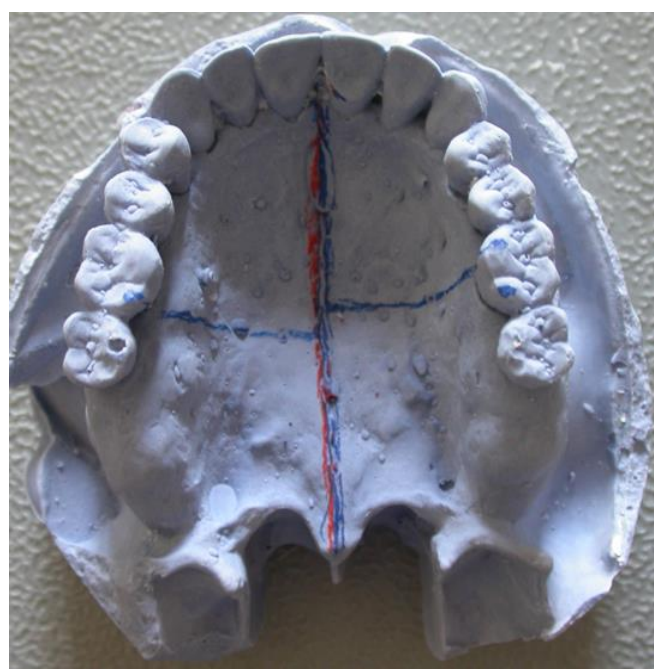

Figure 4. Showed identical ANS-PNS plane with skeletal midline i.e. no midline deviation.

\section{DISCUSSION}

A precise diagnosis and treatment plan are important prerequisites for improving esthetic and functional problems in severe dentofacial deformities. Cephalometric prediction (paper surgery) and cast prediction (model surgery) have been commonly used to simulate orthognathic surgery. Paper surgery allows for the simultaneous evaluation of skeletal and dental movements. Model surgery can provide quantitative and visible 3-dimensional (3D) information on the movement of the dentition, but the information is limited to the dental region ${ }^{15-20}$. Although both methods can provide valuable information, it is sometimes difficult to precisely predict the $3 \mathrm{D}$ movement of bony segments, especially when there is skeletal asymmetry. In cases involving skeletal asymmetry, complicated movements of the segmented bones, including multidirectional translation or rotation with more than 2 rotational axes, are necessary for successful surgery ${ }^{21,22}$.

The use of submentovetix cephalometric radiograph has added the third rotational axes to our model surgery because both the lateral and postroanterior Cephalometric radiographs can't determine the rotation of 
PNS (on the horizontal plane) and in turn can't determine the posterior rotation of maxilla. Molars positions are the same in both the skull and the model, therefore these molars were used as an accurate fixed reference points in determination of midline deviation.

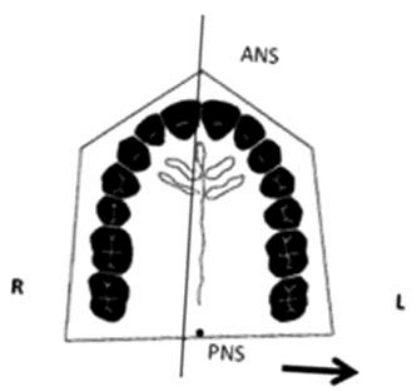

A

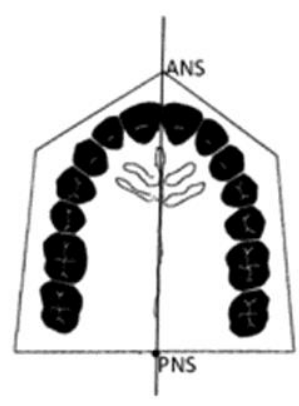

B

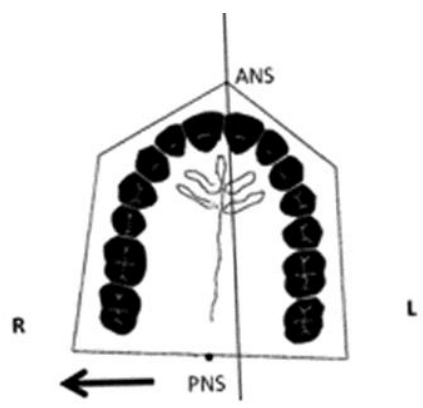

C

Figure 5. A, showed midline deviation to left. B, showed no midline deviation. C, showed midline deviation to the right. In all cases, midline coincide with ANS, but that was not the case with PNS

Adjusting the posterior rotation of maxilla will give many benefits which enrich our model surgery. First, it adjusts the occlusion through correcting the position of the maxillary molars, and in turn, the mandibular molars. Second, adjusting occlusion has good surgical outcomes concerning function, aesthetics and also decreases tempromandiblar joint disorders which may result after orthognathic surgery.

Concerning the recent computerized methods for simulation of surgery, there are three problems involved in the precise transfer of the experience gained and the results of simulation surgery to the patient: (1) 3D models have no precise reference points; (2) it is difficult to measure translations three-dimensionally; and (3) exact transfer to the patient intraoperatively is impossible ${ }^{23}$. What has to be carefully considered also in clinical use is that the anatomical shape of a mandible may not be precisely reproduced ${ }^{24}$.Also, these methods need sophisticate, expensive equipments and software. 
Conclusion: Identification of the PNS and adjusting midline deviation of maxilla will perfect and enrich model surgery procedures especially in asymmetric and bimaxilary surgery cases.

\section{REFERENCES}

1. Hohl TH. The use of an anatomic articulator in segmental orthognathic surgery. Am J Orthod 1978;73(4):428-42.

2. Bamber MA, Harris M. The role of the occlusal wafer in orthognathic surgery; a comparison of thick and thin intermediate osteotomy wafers. J Craniomaxillofac Surg 1995;23(6):396-400.

3. Bamber MA, Harris M, Nacher C. A validation of two orthognathic model surgery techniques. J Orthod 2001;28(2):135-42.

4. Gil JN, Claus JD, Manfro R, Lima SM, Jr. Predictability of maxillary repositioning during bimaxillary surgery: accuracy of a new technique. Int J Oral Maxillofac Surg 2007;36(4):296-300.

5. Ellis E, 3rd, Tharanon W, Gambrell K. Accuracy of face-bow transfer: effect on surgical prediction and postsurgical result. J Oral Maxillofac Surg 1992;50(6):562-7.

6. Reyneke JP, Evans WG. Surgical manipulation of the occlusal plane. Int J Adult Orthodon Orthognath Surg 1990;5(2):99-110.

7. Wolford LM, Chemello PD, Hilliard F. Occlusal plane alteration in orthognathic surgery--Part I: Effects on function and esthetics. Am J Orthod Dentofacial Orthop 1994;106(3):304-16.

8. Chemello PD, Wolford LM, Buschang PH. Occlusal plane alteration in orthognathic surgery--Part II: Long-term stability of results. Am J Orthod Dentofacial Orthop 1994;106(4):434-40.

9. Bowley JF, Michaels GC, Lai TW, Lin PP. Reliability of a facebow transfer procedure. J Prosthet Dent 1992;67(4):491-8.

10. Gold BR, Setchell DJ. An investigation of the reproducibility of face-bow transfers. J Oral Rehabil 1983;10(6):495-503. 
11. Donatsky O, Hillerup S, Bjorn-Jorgensen J, Jacobsen PU. Computerized cephalometric orthognathic surgical simulation, prediction and postoperative evaluation of precision. Int J Oral Maxillofac Surg 1992;21(4):199-203.

12. Maki K, Inou N, Takanishi A, Miller AJ. Computer-assisted simulations in orthodontic diagnosis and the application of a new cone beam X-ray computed tomography. Orthod Craniofac Res 2003;6 Suppl 1:95-101; discussion 79-82.

13. Motohashi N, Kuroda T. A 3D computer-aided design system applied to diagnosis and treatment planning in orthodontics and orthognathic surgery. Eur J Orthod 1999;21(3):263-74.

14. Yosano A, Yamamoto M, Shouno T, Shiiki S, Hamase M, Kasahara K, et al. Model surgery technique for Le Fort I osteotomy-alteration in occlusal plane associated with upward transposition of posterior maxilla. Bull Tokyo Dent Coll 2005;46(3):67-78.

15. Kwon TG, Mori Y, Minami K, Lee SH. Reproducibility of maxillary positioning in Le Fort I osteotomy: a 3-dimensional evaluation. J Oral Maxillofac Surg 2002;60(3):287-93.

16. Turvey T, Hall DJ, Fish LC, Epker BN. Surgical-orthodontic treatment planning for simultaneous mobilization of the maxilla and mandible in the correction of dentofacial deformities. Oral Surg Oral Med Oral Pathol 1982;54(5):491-8.

17. Hill SC. Cephalometric planning and model surgery. In: Bell WH, editor. Surgical correction of dentofacial deformities: new concepts. Philadelphia: W. B. Saunders; 1985. p. 210-26.

18. Proffit WR, White RPJ, Sarver DM. Contemporary treatment of dentofacial deformity. St Louis: C. V. Mosby; 2002.

19. Ellis E, 3rd. Accuracy of model surgery: evaluation of an old technique and introduction of a new one. J Oral Maxillofac Surg 1990;48(11):1161-7.

20. Forsberg CT, Burstone CJ, Hanley KJ. Diagnosis and treatment planning of skeletal asymmetry with the submental-vertical radiograph. Am J Orthod 1984;85(3):224-37. 
Egyptian

Orthodontic Journal

21. Sohmura T, Hojo H, Nakajima M, Wakabayashi K, Nagao M, lida S, et al. Prototype of simulation of orthognathic surgery using a virtual reality haptic device. Int J Oral Maxillofac Surg 2004;33(8):740-50.

22. Choi JY, Choi JH, Kim NK, Kim Y, Lee JK, Kim MK, et al. Analysis of errors in medical rapid prototyping models. Int J Oral Maxillofac Surg 2002;31(1):23-32.

23. Santler G. Computergestützter 3-D-Operationssimulator. Mund Kiefer GesichtsChir 2000;4:39-44.

24. Noguchi N, Goto M. Computer simulation system for orthognathic surgery. Orthod Craniofac Res 2003;6 Suppl 1:176-8. 